\title{
Numerical Analysis of the Non-Stationary Thermal State of the Tool in the Combined Casting and Extrusion of Non-Ferrous Metals
}

\section{Alexander Petrovich Skuratov}

Siberian federal university, Krasnoyarsk

Natal'ya Petrovna Popiyakova

Siberian federal university, Krasnoyarsk

Alexander Sergeevich Potapenko

Siberian federal university, Krasnoyarsk

Yuriy Vasilyevich Gorokhov

Siberian federal university, Krasnoyarsk

Mikhail Yur'yevich Kuchinskii

Siberian federal university, Krasnoyarsk

Sergey Vladimirovich Belyaev

Siberian federal university, Krasnoyarsk

Denis Sergeevich Voroshilov ( $\nabla$ d.s.voroshilov@gmail.com )

Siberian Federal University https://orcid.org/0000-0002-1406-3665

Igor Lazarevich Konstantinov

Siberian federal university, Krasnoyarsk

Alexander Vadimovich Ivlev

Siberian federal university, Krasnoyarsk

Dmitriy Nikolaevich Bozhko

Siberian federal university, Krasnoyarsk

\section{Research Article}

Keywords: Installation, Continuous combined casting-extrusion, Horizontal mold, Computer model, Numerical analysis, Heat transfer, Transient process, Aluminum alloy, Productivity.

Posted Date: April 8th, 2021

DOl: https://doi.org/10.21203/rs.3.rs-389141/v1

License: (a) (i) This work is licensed under a Creative Commons Attribution 4.0 International License. Read Full License 
Version of Record: A version of this preprint was published at The International Journal of Advanced Manufacturing Technology on July 28th, 2021. See the published version at https://doi.org/10.1007/s00170-021-07634-x. 


\title{
Numerical Analysis of the Non-Stationary Thermal State of the Tool in the Combined Casting and Extrusion of Non-Ferrous Metals
}

\author{
Alexander Petrovich Skuratov, Natal'ya Petrovna Popiyakova, Alexander Sergeevich Potapenko, \\ Yuriy Vasilyevich Gorokhov, Mikhail Yur'yevich Kuchinskii, Sergey Vladimirovich Belyaev, \\ Denis Sergeevich Voroshilov*, Igor Lazarevich Konstantinov, Alexander Vadimovich Ivlev, \\ Dmitriy Nikolaevich Bozhko
}

Siberian federal university, Krasnoyarsk, 660025, Krasnoyarsk Region, Russian Federation *E-mail: d.s.voroshilov@gmail.com

\begin{abstract}
The results of a numerical analysis of unsteady heat transfer in the "metal-mold-environment" system during continuous combined casting and extrusion of an aluminum alloy in an installation with a horizontal carousel mold are presented. The heat engineering zones characterized by different intensity of heat transfer between the melt and the surface of the mold have been determined. A quantitative assessment of the influence of the rate of heating of the crystallizer on the temperature-time characteristics during the period of the transient thermal process is given. It is shown that an increase in the productivity of the installation reduces the duration of the transient thermal process when starting the installation from a cold state until it reaches a stationary thermal regime. The dependence of the time at which the installation reaches the stationary thermal regime on the rotation speed of the crystallizer wheel has been obtained.
\end{abstract}

Keywords: Installation, Continuous combined casting-extrusion, Horizontal mold, Computer model, Numerical analysis, Heat transfer, Transient process, Aluminum alloy, Productivity.

\section{Introduction}

The development of technologies for foundry and metal forming is directed towards the unification of several technological stages in one installation [1-8]. These include, for example, a horizontal semi-continuous casting machine (HSCCM) [9]. It should also be noted the improved process of Extrolling of the combination of rolling and extrusion in one deformation zone [10, 21] implemented in the CCRE-2.5 pilot unit.

Widespread, especially in non-ferrous metallurgy, are the Super Caster units of the Italian company Fata-Hunter, a distinctive feature of which are large diameters of crystallizer rolls, which are individually driven by an electric motor through a planetary gearbox [11, 12]. The ingot rolling technology used here is characterized by low capital intensity and low operating costs. However, this technology has a number of disadvantages due to the difficulty of supplying and retaining the metal in the rolls during reductions [13].

The process of discrete extrusion of non-ferrous metal alloys is complex and energyconsuming with the release of a large amount of heat generated by the action of frictional forces and plastic deformation. With an increase in the extruding speed the temperature of the deformed metal increases intensively, and when critical temperatures are reached its destruction occurs [14].

As studies of the methods of continuous extrusion of metals have shown [15-24], their use significantly increases the efficiency of the production of profiles from non-ferrous metals. One of the promising directions in the development of these technologies is the combination of continuous casting with extrusion on a Conform installation with a horizontal carousel mold [21-26]. During the operation of the installation, the metal melt is fed through the batcher into the annular groove of the rotating mold wheel and solidifies to contact with the stationary part of the container, formed at the interface of the groove with the arcuate segment (Fig. 1). The solidified metal is extruded into the die hole in the segment in the form of a press product. The supply of liquid metal into the groove, its solidification and extrusion proceed in a continuous mode [27]. 


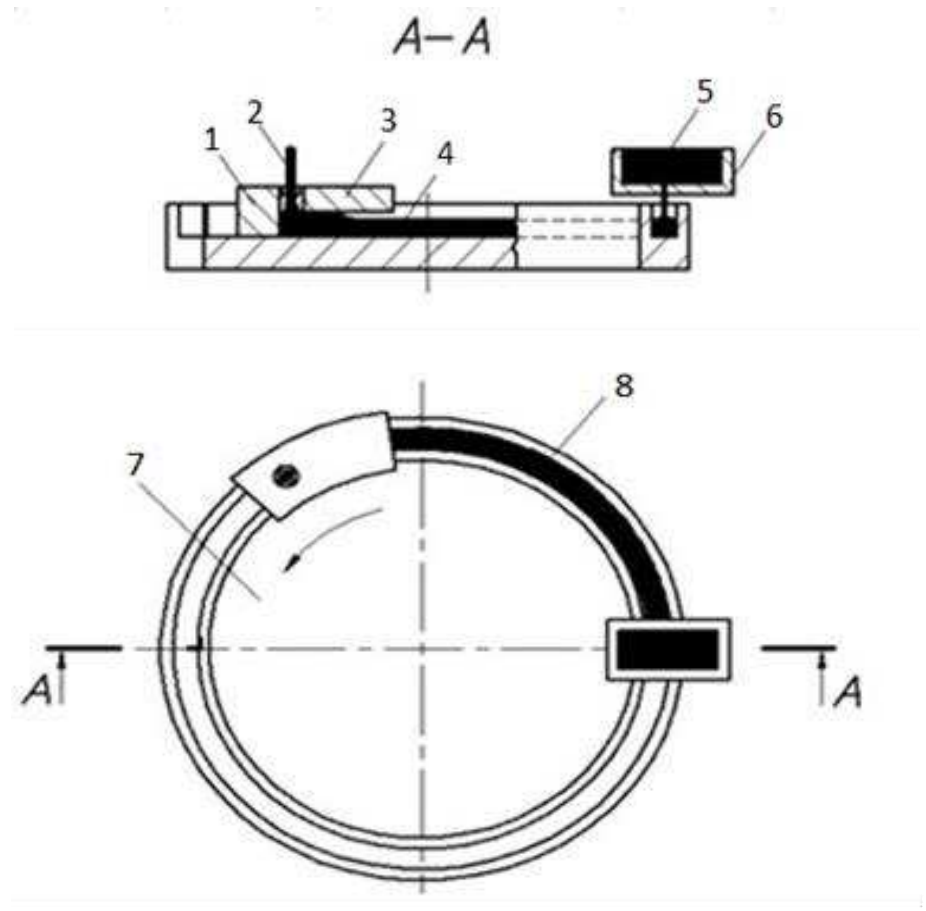

Fig 1. Installation scheme of continuous casting and extrusion with horizontal carousel mold: 1 - die stopper; 2 - press product; 3 - stationary arcuate segment; 4 - solidified ingot;

5 - metal melt; 6 - dispenser; 7 - crystallizer wheel; 8 - annular groove

A necessary condition for combining continuous casting and extrusion of metal is the observance of such thermal conditions in the "metal-crystallizer-environment" system, which ensures the solidification of the melt and stabilization of its temperature in the section in front of the container [28-30]. An analysis of the thermal regimes of continuous casting before extrusion of aluminum alloys carried out on the basis of the method proposed in $[31,32]$ that confirmed this statement.

Further studies of the nature of the dependence of the thermal operation of the "metalcrystallizer-environment" system on the parameters of the technological process showed that in an unstable transient mode the crystallizer wheel gradually warms up with each round from the initial temperature until a stationary thermal state is reached. At the same time on the basis of computer simulation it was found that the degree and rate of heating of the crystallizer in the initial period of operation of the installation have the main effect on the nature of unsteady heat transfer and changes in the enthalpy of the melt $[33,34]$. As a result, operational and design solutions were proposed that ensure rational temperature-time conditions for the installation at a fixed design rotational speed of the mold (the productivity of the installation in terms of the mass flow rate of the melt poured in) in a long-term stable period of its operation [29, 30].

The purpose of this work was to theoretically study unsteady heat transfer to determine the temperature-time conditions of the elements of the system "metal-horizontal crystallizerenvironment" in transient thermal modes of operation of the Conform installation with combined casting-extrusion of an aluminum alloy.

\section{Materials and method of carrying out research}

The analysis of the dynamics of heat transfer in the transient operating mode of the installation was carried out in three calculated sections passing through the volume of the metal and the material of the mold solidifying in the groove. The sections are formed by a vertical cutting plane located at a distance from the pouring point of the melt $P$ at angles $\varphi_{1}=30^{\circ}, \varphi_{2}=120^{\circ}$ and $\varphi_{3}$ $=210^{\circ}$ (Fig. 2). As can be seen, the central angles $\varphi$ i of the circular arc of the mold groove with 
radius $R_{k}=0.175 \mathrm{~m}$ are located between the polar axis $O P$ (segment $O P=R_{k}$ ) and the rays connecting the pole $O$ with the design sections. The $\varphi_{i}$ reading is taken in a clockwise direction.

In accordance with the technological conditions in the control section $\varphi_{3}$, located at an angular distance $\Delta \varphi=15^{\circ}$ from the beginning of the extruding zone (stationary arcuate segment) a temperature range must be provided over the metal section the maximum value of which is $3-5{ }^{\circ} \mathrm{C}$ lower than the solidification temperature aluminum melt [35].

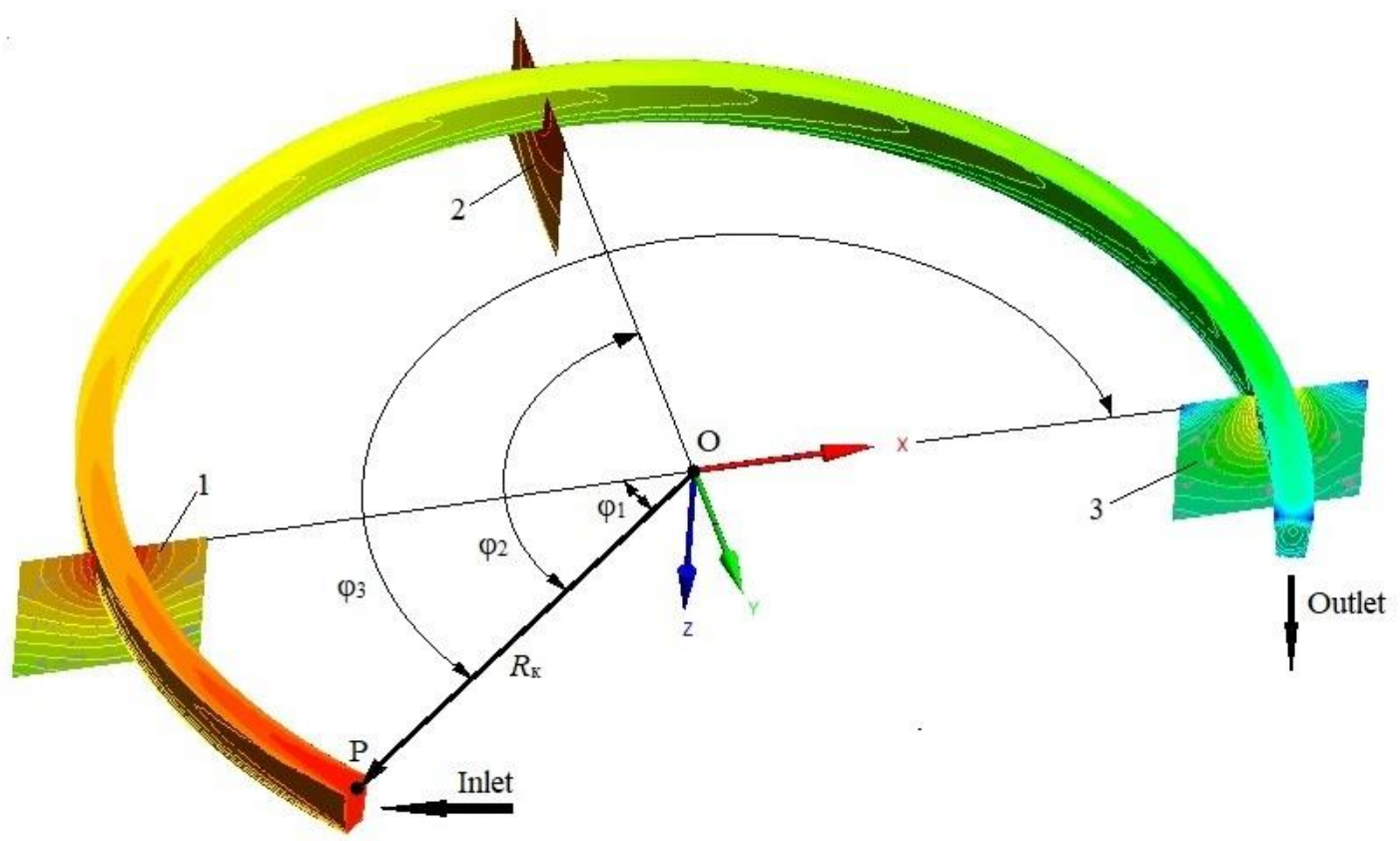

Fig. 2. The layout of the design sections in the body of the horizontal mold from the place of pouring the melt $P: 1,2$ and $3-$ design sections, at central angles $\varphi_{1}=30^{\circ}, \varphi_{2}=120^{\circ}$ and $\varphi_{3}=210^{\circ}$

Numerical studies were carried out on a previously developed three-dimensional computer model of heat transfer in a pilot plant implemented on the basis of software [35-37] SolidWorks (2017) and Ansys CFX 17.1.

Nonlinear differential equations for the conservation of energy for the processed melt and the elements of the installation were written in the form of a substantial derivative:

$$
\rho_{i} c_{i}(t) \frac{D t_{i}}{d \tau}=\rho_{i} c_{i}(t) \frac{\partial t_{i}}{d \tau}+\rho_{i} c_{i}(t) \operatorname{div}\left(w_{i} t_{i}\right)=\lambda_{i} \nabla^{2} t_{i}+q_{v i}
$$

where $t_{i}$ is the temperature field in the $i$-th element; $\rho_{i}, c_{i}$ and $\lambda_{i}$-density, volumetric heat capacity and thermal conductivity of the $i$-th element; $w_{i}$ is the vector of the angular velocity of motion of the $i$-th element in the body of the mold and the melt; $q_{v i}$ is a function characterizing heat sources (internal heat release during phase transition and metal pressing) in the $i$-th element [38]:

$$
q_{v i}=S_{h}{ }^{\prime}+S_{h}{ }^{\prime},
$$

where $S_{h}{ }^{\prime}$ - internal heat release during phase transition; $S_{h}{ }^{\prime}$ - heat release from the forces of contact friction and deformation forces of the metal being processed.

In the mathematical model a cylindrical coordinate system was used (Fig. 2), where the divergence and Laplace operator included in the system of differential equations (1) had the following form: 


$$
\begin{aligned}
& \operatorname{div}=\frac{\partial}{\partial R}+\frac{1}{R}+\frac{1}{R} \frac{\partial}{\partial \varphi}+\frac{\partial}{\partial z} \\
& \nabla^{2} t_{i}=\left\{\frac{\partial^{2} t_{i}}{\partial R_{i}^{2}}+\frac{1}{R_{i}} \frac{\partial t_{i}}{\partial R_{i}}+\frac{1}{R_{i}^{2}} \frac{\partial^{2} t_{i}}{\partial \varphi_{i}^{2}}+\frac{\partial^{2} t_{i}}{\partial z_{i}^{2}}\right\} .
\end{aligned}
$$

Equation (1) was supplemented by the boundary conditions:

$$
t_{i}=t_{0}(R, z, \varphi, \tau=0) ; w_{i}=(R, z, \varphi, \tau)=\mathrm{const} ;\left.\lambda \frac{\partial t}{\partial n}\right|_{\Gamma_{i}}= \pm q_{i} .
$$

Here $q_{i}$ - function characterizing the conditions of radiation-convective heat transfer at the boundary of the surface of the $i$-th element $\Gamma_{i}\left(q_{i}>0\right.$ - heat flux is directed inside the element).

In the boundary conditions (5) the angular velocity of movement of the installation elements $w_{i}$ relative to the $Z$ axis of the system will change: the mold wheel with the melt solidifying in its groove, the other elements of the design model are stationary $\left(w_{i}=0\right)$. The enthalpy of the melt poured into the groove of the crystallizer is calculated based on the accepted initial values of its temperature and flow rate which is functionally related to the value of $w_{i}$.

\section{Results and discussion}

A numerical study of the process of continuous combined casting-extrusion was carried out for the eutectic aluminum alloy Al12Si with a melting (solidification) temperature of $580{ }^{\circ} \mathrm{C}$. When analyzing the temperature-time characteristics of the transient thermal process the speed of rotation of the crystallizer wheel $w_{c}$ was taken as the operating parameter, the range of which varied within 1-3 rpm. The temperature $t_{p}$ of the metal melt poured into the groove was taken equal to $750{ }^{\circ} \mathrm{C}$, the ambient temperature was $20^{\circ} \mathrm{C}$.

In accordance with the specified value $w_{k}$ and the dimensions of the section of the mold groove $10 \times 10 \mathrm{~mm}$, the mass flow rate of the melt (unit productivity) $G_{p}$ took values $0.27-0.81$ $\mathrm{kg} / \mathrm{min}$. Note that in proportion to the value of $G_{p}$ in equation (1) the amount of heat supplied with the poured metal to the elements of the installation also changed.

The results of modeling the dynamics of heat transfer in a transient thermal process indicate a significant effect of the rotation speed of the horizontal mold wheel on the rate of its heating and, as a consequence, on the nature of the temperature field in the tool body and solidifying melt.

Fig. 3 shows the isotherms $t_{1}, t_{2}$, and $t_{3}$ calculated during the transient thermal process corresponding to the temperature value over the cross section of the mold body 700, 650, and 600 ${ }^{\circ} \mathrm{C}$, at $t_{p}=750{ }^{\circ} \mathrm{C}$ and the rotation speed of the mold wheel $w_{c}=1$ and $3 \mathrm{rpm}$.
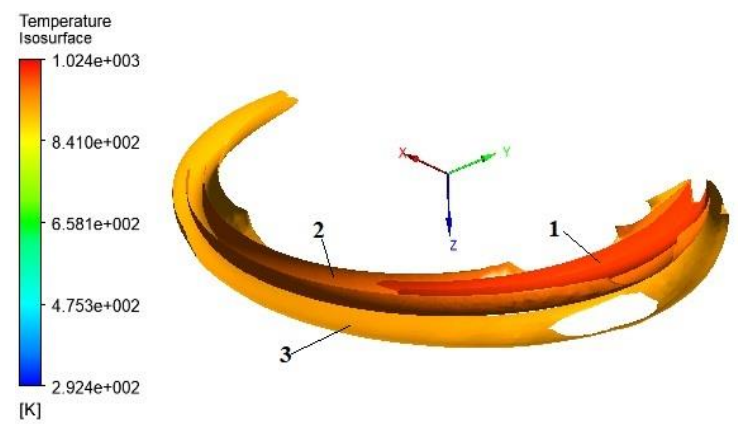

$a$

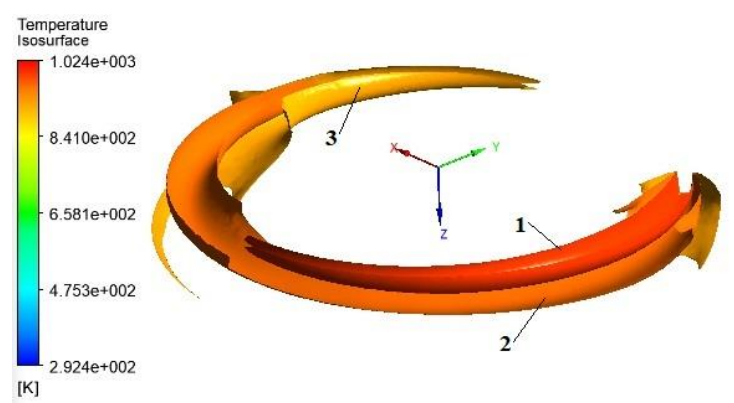

$b$ 

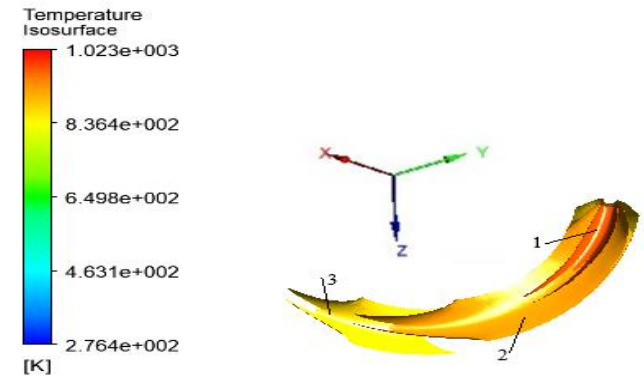

$c$
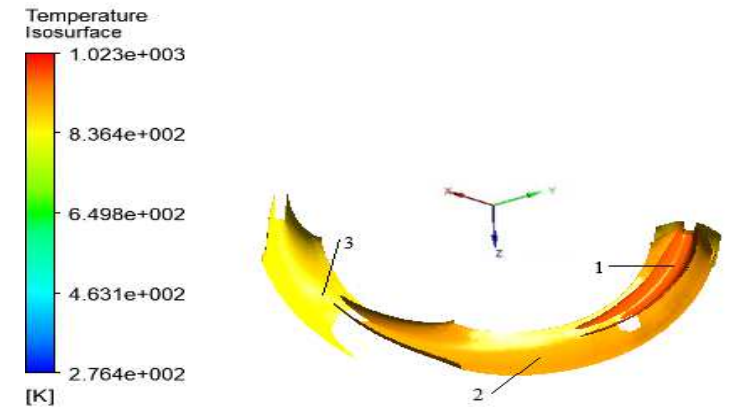

$d$

Fig. 3. The values of the isotherms $t_{i}$ in the body of the mold in the transient thermal process at $t_{p}=750^{\circ} \mathrm{C}$ :

$$
\begin{gathered}
1-t_{1}=700{ }^{\circ} \mathrm{C} ; 2-t_{2}=650{ }^{\circ} \mathrm{C} ; 3-t_{3}=600{ }^{\circ} \mathrm{C} ; \\
a-\tau_{e x}=320 \mathrm{~s}, w_{k}=3 \mathrm{rpm} ; b-\tau_{e x}=840 \mathrm{~s}, w_{k}=3 \mathrm{rpm} ; \\
c-\tau_{e x}=320 \mathrm{~s}, w_{k}=1 \mathrm{rpm} ; d-\tau_{e x}=840 \mathrm{~s}, w_{k}=1 \mathrm{rpm}
\end{gathered}
$$

As can be seen, during the transient thermal process $\tau_{e x}$ the location of the considered isotherms changes, associated with a different rate of heating of the mold. So, for example, an isotherm with a temperature of $t_{1}=700{ }^{\circ} \mathrm{C}$ during periods of time $\tau_{e x}=320$ and $840 \mathrm{~s}$, at a mold rotation speed $w_{\kappa}=3 \mathrm{rpm}$, the length of an arc segment $\Delta \varphi_{i}$ from the pouring point of the melt $P$ (Fig. 2) equal to 0.066 and $0.115 \mathrm{~m}$ respectively. At $w_{\kappa}=1 \mathrm{rpm}$ the arc distance $\Delta \varphi_{i}$ changes significantly and the length of the arc segments for the considered time periods $\tau_{e x}$ decreases to 0.025 and $0.045 \mathrm{~m}$ respectively.

Analysis shows that at the initial moment of time after the start-up of the installation in the "melt - tool" system, the bulk of the heat goes to heating the mold (Fig. 3). In this case, the more heat is supplied with the melt the faster the crystallizer heats up and, accordingly, the time for reaching the stationary thermal mode of operation of the installation as a whole decreases. It has been determined that when the rotation speed of the mold changes from 1 to $3 \mathrm{rpm}$, the time to reach the stationary thermal regime $\left(\tau_{s t}\right)$ decreases almost three times (from 46 to 15 minutes).

It was found that in the transient thermal process, the crystallizer has two temperature-time heating zones the characteristics of which depend on the productivity of the installation.

In the first zone intense heat exchange occurs between the metal melt and the walls of the mold wheel. The analysis shows that at $\mathrm{tp}=750{ }^{\circ} \mathrm{C}$ and $G_{p}=0.81 \mathrm{~kg} / \mathrm{min}\left(w_{\kappa}=3 \mathrm{rpm}\right)$, the time interval from the start of the installation to the passage of this zone $\Delta \tau_{e x}$ is $320 \mathrm{~s}$. In this case the rate of change of the average temperature of the mold in the first design section along its rotation $\left(\varphi_{1}\right)$ $\Delta \bar{t}_{k} / \Delta \tau_{e x}=15.3^{\circ} \mathrm{C} / \mathrm{min}$ and the maximum temperature gradient between the wall of the mold and the peripheral layer of the melt in the groove grad $t_{\text {mold }}=87^{\circ} \mathrm{C} / \mathrm{mm}$ (Fig. 4) 


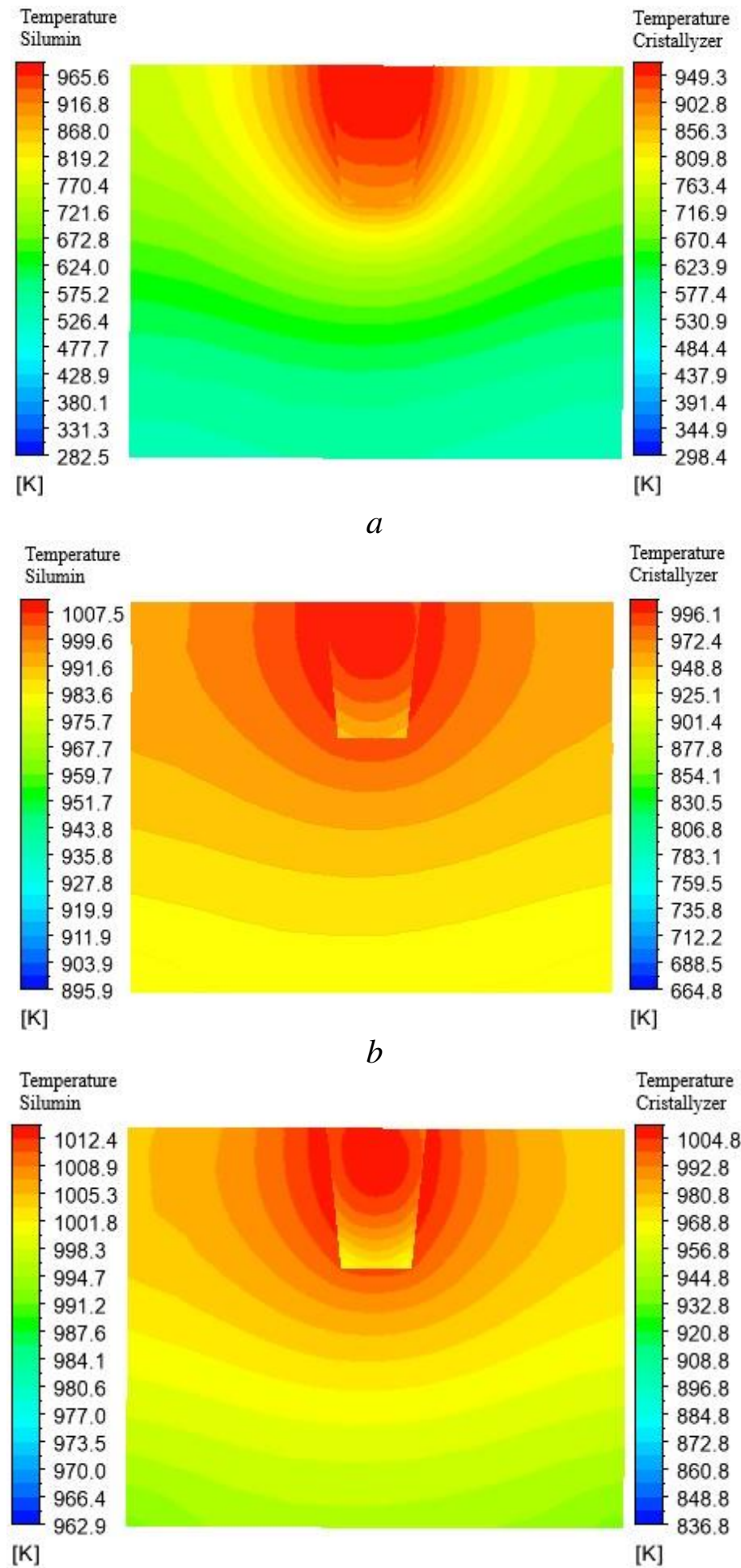

$c$

Fig. 4. Temperature field $(\mathrm{K})$ in the design section of the metal and the mold $\varphi_{1}=30^{\circ}$ at $t_{p}=750{ }^{\circ} \mathrm{C}, w_{k}=3 \mathrm{rpm}$ :

$$
a-\tau_{e x}=60 \mathrm{~s} ; b-\tau_{e x}=320 \mathrm{~s} ; c-\text { stationary thermal regime }
$$

Calculations have shown that a decrease in the productivity of the installation to $G_{p}=0.27$ $\mathrm{kg} / \mathrm{min}\left(w_{k}=1 \mathrm{rpm}\right)$ increases the duration of the first temperature-time zone $\Delta \tau_{e x}$ to $450 \mathrm{~s}$. At the same time the value of the parameters $\Delta t_{k} / \Delta \tau_{e x}$ and grad $t_{m o l d}$ noticeably decrease the values of which in the section $\varphi_{1}$ are $4.78{ }^{\circ} \mathrm{C} / \mathrm{min}$ and $23^{\circ} \mathrm{C} / \mathrm{mm}$ respectively (Fig. 5). 
In the second zone, the rate of heat removal from the melt to the mold decreases, and the length of the arc of solidification of the melt increases. So, in the considered section $\varphi_{1}$ at $w_{k}=3$ $\mathrm{rpm}$, the values and $\Delta t_{k} / \Delta \tau_{\text {ex }} \operatorname{grad} t_{m o l d}$ decrease to $4.5^{\circ} \mathrm{C} / \mathrm{min}$ and $2.3^{\circ} \mathrm{C} / \mathrm{mm}$ respectively. At $w_{k}=$ $1 \mathrm{rpm}$, these values take the corresponding values of $1.82^{\circ} \mathrm{C} / \mathrm{min}$ and $4.2^{\circ} \mathrm{C} / \mathrm{mm}$.

Fig. 6 shows the generalized temperature-time dependences obtained during the period of the transient thermal process at different productivity of the installation in the calculated sections $\varphi_{i}$ of the crystallizer body and the solidifying melt.

It can be seen that the nature of the temperature field of the mold and the metal changes both during $\Delta \tau_{e x}$ from the start of the installation until it reaches a stationary thermal regime and in the course of their movement from the pouring point to the pressing zone. With an increase in the productivity of the installation the temperature of the mold and the alloy being processed increases in the design sections $\varphi_{i}$ which is associated with an increase in the heat supplied to the castingextrusion process with the poured melt.

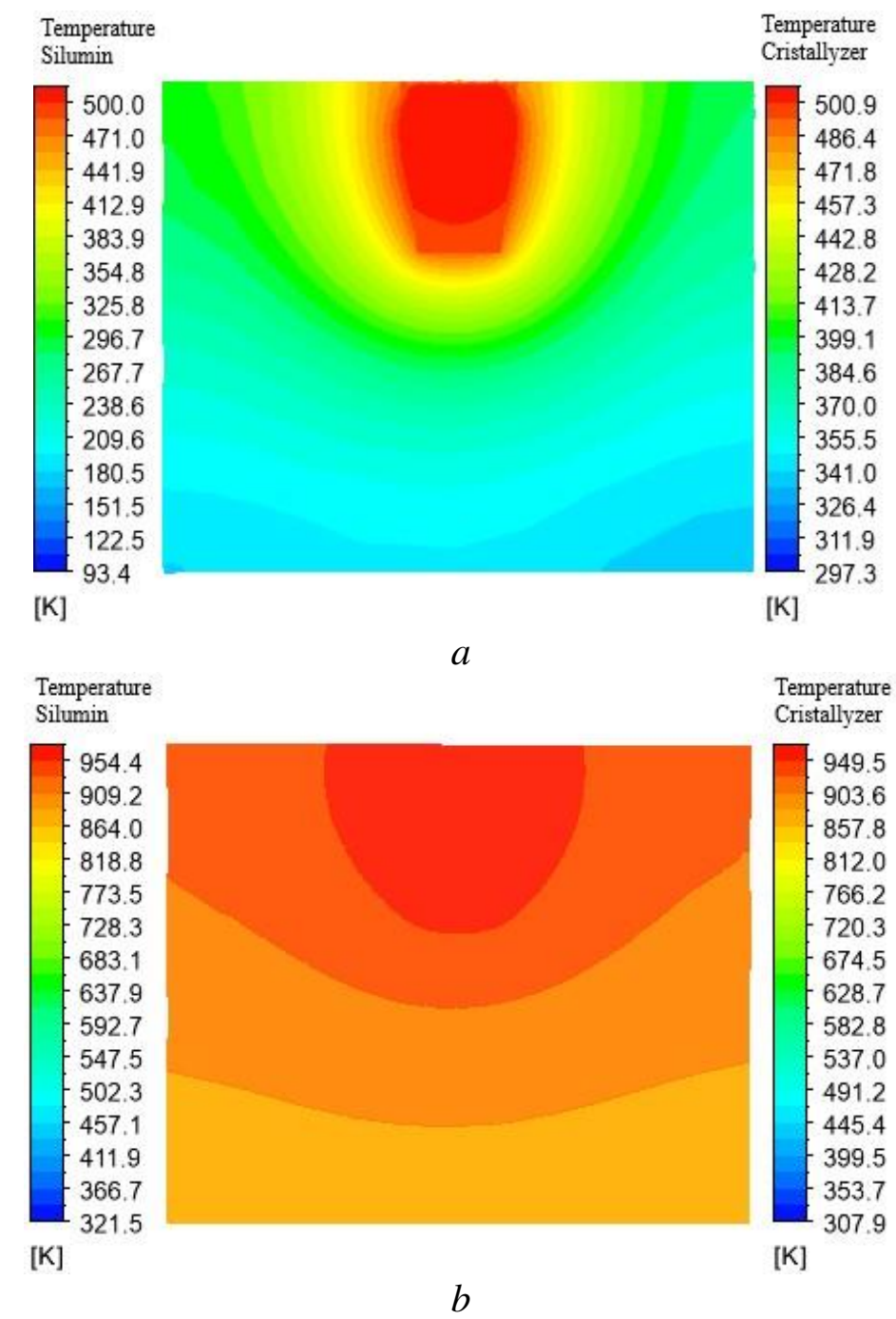




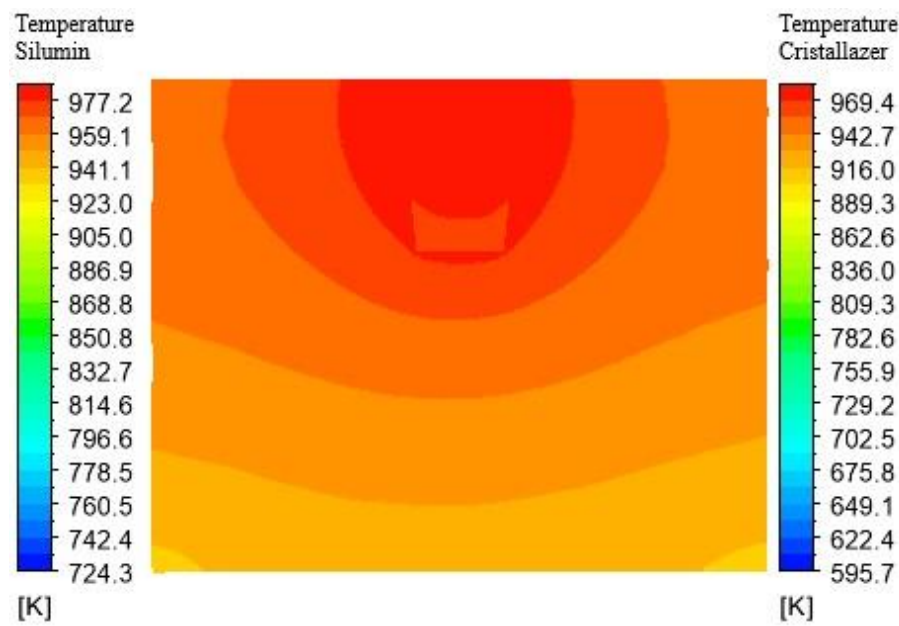

C

Fig. 5. Temperature field $(\mathrm{K})$ in the design section of the metal and the mold $\varphi_{1}=30^{\circ}$ at $t_{p}=750{ }^{\circ} \mathrm{C}, w_{k}=1 \mathrm{rpm}$ :

$a-\tau_{e x}=60 \mathrm{~s} ; b-\tau_{e x}=450 \mathrm{~s} ; c-$ stationary thermal regime

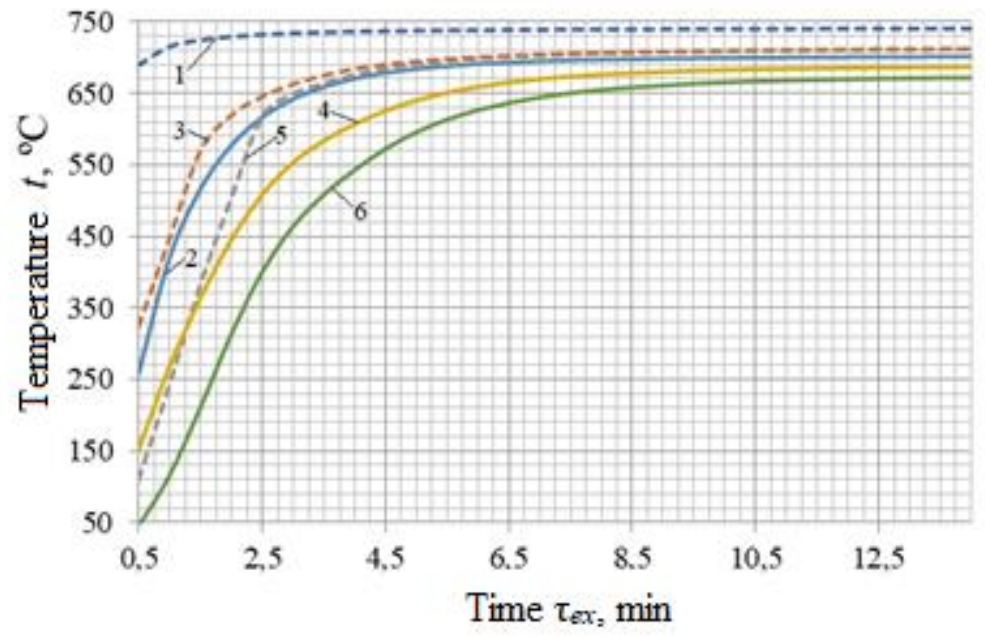

$a$

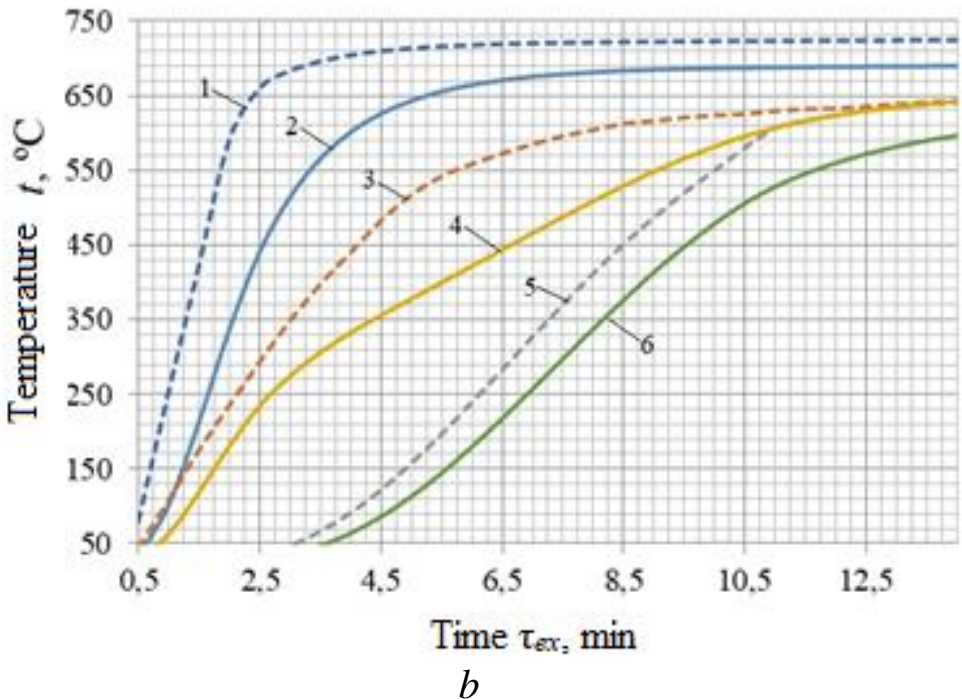




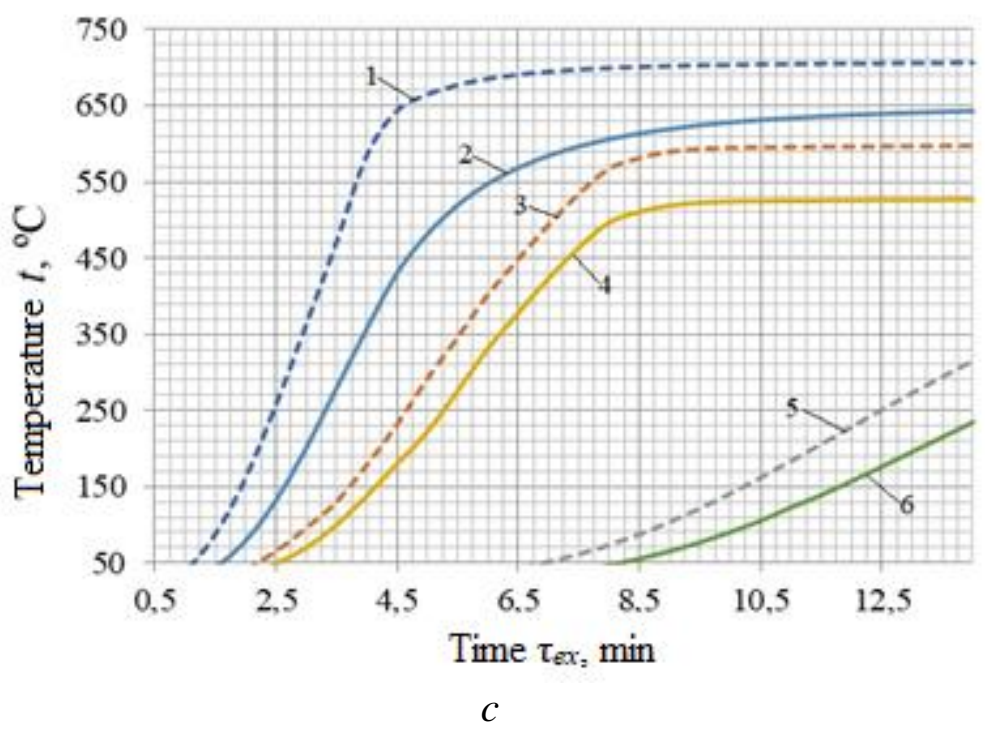

Fig. 6. Temperature change in the body of the mold and metal in the design sections $\varphi_{i}$ in transient thermal mode:

1,2 - temperature of metal and mold at $w_{k}=3 \mathrm{rpm}$;

$3,4-$ temperature of metal and mold at $w_{k}=2 \mathrm{rpm}$;

5,6 - temperature of metal and mold at $w_{k}=1 \mathrm{rpm}$; $a-\varphi_{1}=30^{\circ} ; b-\varphi_{2}=120^{\circ} ; c-\varphi_{3}=210^{\circ}$

With an increase in the rotational speed of the mold up to $3 \mathrm{rpm}$ during the period of the transient process, the asymmetry of the temperature field in the calculated sections of the metal $\varphi_{2}$ and $\varphi_{3}$ increases. The region with the maximum temperature is shifted to the surface layers of the metal in contact with the environment. When the speed decreases to $1 \mathrm{rpm}$ the shift of the temperature field with the maximum temperature over the metal cross section is insignificant. In the design sections $\varphi_{2}$ and $\varphi_{3}$ the region with the maximum temperature shifts towards their central part.

It should be noted that at $w_{k} \leq 1.75 \mathrm{rpm}$ the design of the installation upon reaching a stationary thermal regime provides in the third control section $\varphi_{3}$ in front of the extrusion zone the temperature of the solidifying melt below the point of its phase transition due to sufficient heat removal into the environment.

\section{Summary}

1. A numerical study of unsteady heat transfer during continuous combined castingextrusion of an aluminum eutectic alloy Al12Si was carried out, on the basis of which two temperature-time zones were determined in transient thermal modes of operation of the Conform installation.

2. The dependence of the time at which the installation reaches a stationary thermal regime on the rotation speed of the crystallizer wheel $w_{k}$ at start-up from a cold state has been obtained.

3. It was found that during the transient thermal process the character of the temperature field in the body of the tool and the solidifying melt is significantly affected by the value of $w k$. So, with its increase, an increase in the asymmetry of the temperature distribution in the calculated sections of the metal near the extruding zone is observed with a shift of the region of maximum values to its surface layers.

4. It is shown that an increase in the productivity of the installation in terms of the mass flow rate of the poured melt is accompanied by an almost linear reduction in the time of the transient thermal process from the start-up of the installation to its stationary mode of operation.

\section{Declarations}




\section{Ethical Approval}

The work contains no libelous or unlawful statements, does not infringe on the rights of others, or contain material or instructions that might cause harm or injury.

\section{Consent to Participate}

The authors consent to participate.

\section{Consent to Publish}

The authors consent to publish.

\section{Authors Contributions}

The authors declare that they are all participants in the work and none of them performed only administrative functions.

\section{Funding}

The reported study was funded by RFBR, the Government of Krasnoyarsk Territory, Krasnoyarsk Regional Fund and LLC «Research and Production Center of Magnetic Hydrodynamics», project number 20-48-242903.

\section{Competing Interests}

The authors declare about the absence of competing interests.

\section{Availability of data and materials}

Not applicable.

\section{References}

1. José Renê de Sousa Rocha, Emerson Edilson Barros de Souza, Francisco Marcondes, Jose Adilson de Castro, Modeling and computational simulation of fluid flow, heat transfer and inclusions trajectories in a tundish of a steel continuous casting machine. Journal of Materials Research and Technology, 2019, 8(5), 4209-4220. DOI: https://doi.org/10.1016/j.jmrt.2019.07.029 Accessed 25 Mar 2021

2. Yanbin Jiang, Xiaodong Mao, Yu Lei, Xinhua Liu, Jianxin Xie, Microstructure and

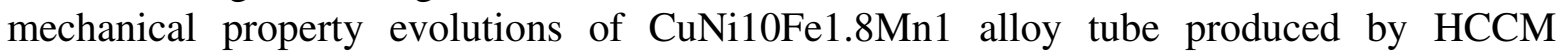
horizontal continuous casting during drawing and its deformation mechanism. Journal of Alloys and Compounds, 2019, 771, 905-913. DOI: https://doi.org/10.1016/j.jallcom.2018.09.041 Accessed 25 Mar 2021

3. Reznik P.L., Ovsyannikov B.V., Influence of homogenization heat treatment and cooling modes on microstructure of AA7475 aluminum alloy ingot. Materials Science Forum, 2020, 989, 335-340. DOI: https://doi.org/10.4028/www.scientific.net/MSF.989.335 Accessed 25 Mar 2021

4. Wang F., Ma Q., Meng W., Han Z., Experimental study on the heat transfer behavior and contact pressure at the casting-mold interface in squeeze casting of aluminum alloy. International Journal of Heat and Mass Transfer, 2017, 112, 1032-1043. DOI: https://doi.org/10.1016/j.ijheatmasstransfer.2017.05.051 Accessed 25 Mar 2021

5. Luo Y., Zhang Z., Numerical modeling of annular electromagnetic stirring with intercooling in direct chill casting of 7005 aluminum alloy billet. Progress in Natural Science: Materials International, 2019, 29(1), 81-87. DOI: https://doi.org/10.1016/j.pnsc.2019.01.007 Accessed 25 Mar 2021

6. Garg P., Jamwal A., Kumar D., Sadasivuni K.K., Hussain C.M., Gupta P., Advance research progresses in aluminium matrixcomposites: Manufacturing \& applications. Journal of 
Materials Research and Technology, 2019, 8(5), 4924-4939. DOI: https://doi.org/10.1016/j.jmrt.2019.06.028 Accessed 25 Mar 2021

7. Cheng $\mathrm{Gu}$, Yan Lu, Emre Cinkilic, Jiashi Miao, Alan A. Luo, Predicting grain structure in high pressure die casting of aluminum alloys: A coupled cellular automaton and process model. Computational Materials Science, 2019, 161, 64-75. DOI: https://doi.org/10.1016/j.commatsci.2019.01.029 Accessed 25 Mar 2021

8. Xixi Dong, Hailin Yang, Xiangzhen Zhu, Shouxun Ji, High strength and ductility aluminium alloy processed by high pressure die casting. Journal of Alloys and Compounds, 2019, 773, 86-96. DOI: https://doi.org/10.1016/j.jallcom.2018.09.260 Accessed 25 Mar 2021

9. Kryukov I.Yu., Naumova M.G., Vdovin K.N., Larina T.P., Development of mathematical model of thermal state of crystallizing blank rectangular in shape in horizontal semicontinuous casting machine. Fundamental research, 2016, 10, 306-311. https://www.fundamental-research.ru/en/article/view?id=40850 Accessed 25 Mar 2021

10. Dovzenko Nikolay N., Sidelnikov Sergey B., Belyaev Sergey V., Soldatov Sergey V., Bespalov Vadim M., Leonov, Victor V., Improvement of Construction of the Pilot Industrial Plant SLIPP-2,5. Journal of Siberian Federal University. Engineering \& Technologies, 2012, 5(7), 817-828. http://elib.sfukras.ru/bitstream/handle/2311/9537/16_Dovzenko.pdf;jsessionid=3650F3307F352954C5A3 09BCEAEA9E1C?sequence=1 Accessed 25 Mar 2021

11. Rappaz, M., Jarry, P., Kurtuldu, G., Zollinger, J., Solidification of Metallic Alloys: Does the Structure of the Liquid Matter? Metallurgical and Materials Transactions A: Physical Metallurgy and Materials Science, 2020, 51, 2651-2664. DOI: https://doi.org/10.1007/s11661-020-05770-9 Accessed 25 Mar 2021

12. Philippe Jarry, Michel Rappaz. Recent advances in the metallurgy of aluminium alloys. Part I: Solidification and casting | Développements récents en métallurgie des alliages d'aluminium. Première partie : coulée et solidification. Comptes Rendus Physique, 2018, 19(8), 672-687. DOI: https://doi.org/10.1016/j.crhy.2018.09.003 Accessed 25 Mar 2021

13. Mitsuo Niinomi, Casting. Metals for Biomedical Devices, 2019, 2, 311-330. DOI: https://doi.org/10.1016/B978-0-08-102666-3.00011-0 Accessed 25 Mar 2021

14. Jensrud O., High strength aluminium alloys extrusions - A review of the thermomechanical-process in high performance profile manufacturing. Key Engineering Materials, 2012, 491, 11-18. DOI: https://doi.org/10.4028/www.scientific.net/KEM.491.11 Accessed 25 Mar 2021

15. Yun X.-B., Yao M.-L., Wu Y., Song B.-Y., Numerical simulation of continuous extrusion extending forming under the large expansion ratio for copper strip. Applied Mechanics and Materials, 2011, 80-81, 91-95. DOI: https://doi.org/10.4028/www.scientific.net/AMM.80$\underline{81.91}$ Accessed 25 Mar 2021

16. Mitka M., Gawlik M., Bigaj M., Szymanski W., Continuous Rotary Extrusion (CRE) of Flat Sections from 6063 Alloy. Key Engineering Materials, 2014, 641, 183-189. DOI: https://doi.org/10.4028/www.scientific.net/KEM.641.183 Accessed 25 Mar 2021

17. Popescu I.N., Bratu V., Rosso M., Popescu C., Stoian E.V., Designing and continuous extrusion forming of Al-Mg-Si contact lines for electric railway. Journal of Optoelectronics and Advanced Materials, 2013, 15(7-8), 712-717.

18. Zhao Y., Song B.-Y., Yun X.-B., Pei J.-Y., Jia C.-B., Yan Z.-Y., Effect of process parameters on sheath forming of continuous extrusion sheathing of aluminum. Transactions of Nonferrous Metals Society of China (English Edition), 2012, 22 (12), 3073-3080. DOI: https://doi.org/10.1016/S1003-6326(11)61573-2 Accessed 25 Mar 2021

19. Zhao D., Lü S., Li J., Guo W., Wu S., A novel continuous squeeze casting-extrusion process for grain refinement and property improvement in AZ31 alloy. Materials Science and 
Engineering A, 2021, 808,140942. DOI: https://doi.org/10.1016/j.msea.2021.140942 Accessed 25 Mar 2021

20. Fastikovskiy A.R., Selivanova E.V., Fedorov A.A., Peretyatko V.N., Evstifeev V.V., Efimov O.Yu., Improvement of continuous forming the "Conform" method. IOP Conference Series: Materials Science and Engineering, 2018, 411(1), 012082. DOI: 10.1088/1757899X/411/1/012082

21. Sidelnikov S.B., Galiev R.I., Bersenev A.S., Voroshilov D.S., Application and Research Twin Roll Casting-Extruding Process for Production Longish Deformed Semi-Finished Products from Aluminum Alloys. Materials Science Forum, 2018, 918, 13-20. https://doi.org/10.4028/www.scientific.net/MSF.918.13. Accessed 25 Mar 2021

22. Ji C., Huang H., A review of the twin-roll casting process for complex section products. ISIJ $\begin{array}{lll}\text { International, } & 2020, & 60(10),\end{array}$ https://www.jstage.jst.go.jp/article/isijinternational/60/10/60_ISIJINT-2020-149/_article. Accessed 18 Mar 2021

23. Sidelnikov S., Sokolov R., Voroshilov D., Motkov M., Bespalov V., Voroshilova M., Sokolova S., Rudnitskiy E., Lebedeva O., Borisyuk V., Modeling the Process of Obtaining Bars from Aluminum Alloy 01417 by Combined Rolling-Extruding Method with Application of the Deform-3D Complex. Key Engineering Materials, 2020, 861, 540-546. https://doi.org/10.4028/www.scientific.net/KEM.861.540. Accessed 18 Mar 2021

24. S.B. Sidelnikov, D.S. Voroshilov, M.V. Pervukhin, M.M. Motkov, Development and research of technology for producing electrotechnical wire from alloys of the $\mathrm{Al}$ - REM system, obtained with the application of combined machining methods. Tsvetnye metally, 2019, 9, 63-68. https://www.rudmet.ru/journal/1853/article/31547/ Accessed 18 Mar 2021

25. Yu.V. Gorokhov, S.V. Belyaev, I.V. Uskov, I.L. Konstantinov, I.Yu. Gubanov, T.Yu. Gorokhova, P.A. Hramtsov, Application of combined casting-pressing for the fabrication of aluminum wire for soldering waveguides. Russian Journal of Non-Ferrous Metals, 2017, 58(1), 75-79. DOI: https://doi.org/10.3103/S1067821217010059 Accessed 25 Mar 2021

26. Zhang X., Guan R., Cui T., Zhou T., Microstructure and mechanical properties of Al-Mg-Sc alloy processed by semi-solid continuous casting-extrusion. Advanced Materials Research, 2011, 299-300, 139-142. DOI: https://doi.org/10.4028/www.scientific.net/AMR.299-300.139 Accessed 25 Mar 2021

27. Skuratov A.P., Gorokhov Yu.V., Potapenko A.S., Belyaev S.V., Gubanov I.Yu., Ivanov A.G. Thermal control device for continuous casting and pressing of non-ferrous metals and alloys: Pat. 2657396 (RF). 2018.

28. Potapenko A.S., Skuratov A.P., Gorokhov Yu.V., Aluminum alloy solidification dynamics under transient heat mode of continuous casting and moulding equipment. Proceedings of Irkutsk State Technical University, 2017, 21(7), 109-118. http://journals.istu.edu/vestnik_irgtu/journals/2017/07/articles/10 Accessed 25 Mar 2021

29. Skuratov Aleksandr P., Potapenko Aleksandr S., Gorokhov Yuri V., The Research of Thermal Operations in the Equipment of Continual Casting \& Aluminum Extrusion in Transitional Mode. Journal of Siberian Federal University. Engineering \& Technologies, 2017, 10(3), 337-345. $\underline{\text { http://elib.sfu- }}$ kras.ru/bitstream/handle/2311/32627/05_Skuratov.pdf?sequence=1 Accessed 25 Mar 2021

30. Skuratov, A.P., Potapenko, A.S., Gorokhov, Y.V., Popiyakova, N.P., Numerical Investigation into the Influence of Overheating of Aluminum Melt on the Heat Exchange in the Continuous Combined Casting and Pressing. Russian Journal of Non-Ferrous Metals, 2019, 60(3), 225-231. DOI: https://doi.org/10.3103/S1067821219030143 Accessed 25 Mar 2021

31. Gorokhov Y.V., Skuratov A.P., Belyaev S.V., Gubanov I.Y., Uskov I.V., Lesiv E.M., Ivanov A.G., Kirko V.I., Koptseva N.P., Potapenko A.S., Analysis of combined metal 
casting thermal conditions: The pressing process during conform installation. ARPN Journal of Engineering and Applied Sciences, 2017, 12(16), 4742-4746.

32. V.Yu. Stetsenko, Mechanisms of the crystallization process of metals and alloys. Casting and Metallurgy, 2013, 1, 48-54.

33. M.Yu. Semashko, P.A. Chigintsev, A comprehensive study of the process of severe plastic deformation of aluminum alloy. Bulletin of the South Ural State University. Ser. Metallurgy, 2016, 16(2) 63-67. (in Russ.) DOI: 10.14529/met160209

34. E.E. Fomina, N.K. Zhiganov, A modification of the simpler algorithm for solving the problem of modeling the process of continuous casting of non-ferrous metals. The Bulletin of Voronezh State Technical University, 2016, 12(1), 32-35. https://cchgeu.ru/science/nauchnye-izdaniya/vestnik-voronezhskogo-gosudarstvennogotekhnicheskogo-universiteta-/fayly/vypuski/12_1.pdf Accessed 25 Mar 2021

35. Minakov A.V., Pervukhin M.V., Platonov D.V., Khatsayuk M.Y., Mathematical model and numerical simulation of aluminum casting and solidification in magnetic fields with allowance for free surface dynamics. Computational Mathematics and Mathematical Physics, 2015, 55, 2066-2079. DOI: https://doi.org/10.1134/S096554251512009X Accessed 25 Mar 2021

36. A.K. Torgovets, I.A. Pikalova, Yu.S. Yusupova, Simulation in continuous casting processes. Karaganda State Industrial University, 2016, 6(28), 88-95.

37. Ershov A.A., Loginov Y.N., Simulation of the Conform-Type Pressing Process by Using the QFORM VX Software Complex. Metallurgist, 2018, 62(3-4), 207-211. DOI: https://doi.org/10.1007/s11015-018-0646-6 Accessed 25 Mar 2021

38. Yu.V. Gorokhov, V.G. Sherkunov, N.N. Dovzhenko et al., Fundamentals of designing processes for continuous extrusion of metals: monograph. Krasnoyarsk: SibFU, 2013. 


\section{Figures}
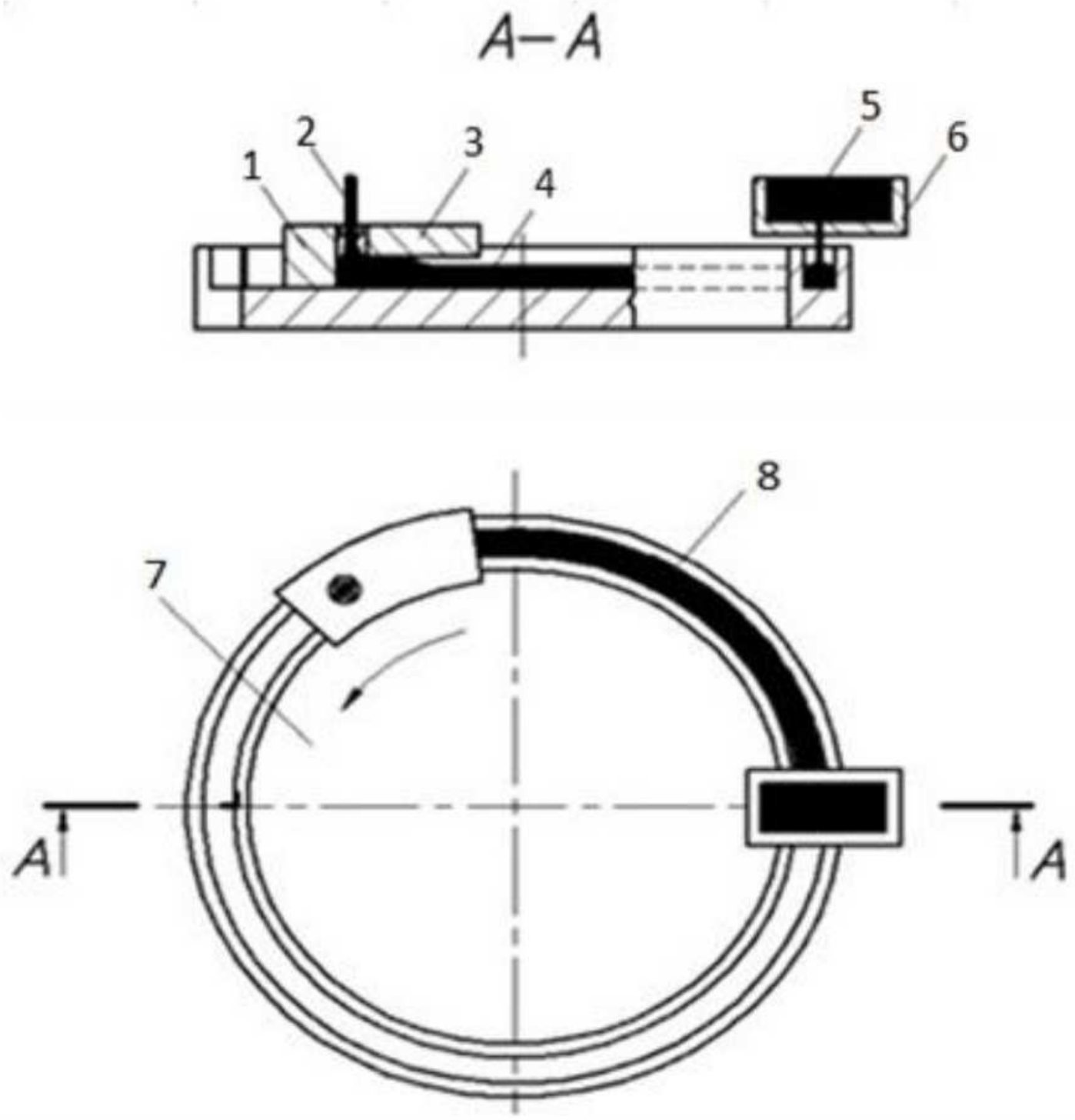

Figure 1

Installation scheme of continuous casting and extrusion with horizontal carousel mold: 1 - die stopper; 2

- press product; 3 - stationary arcuate segment; 4 - solidified ingot; 5 - metal melt; 6 - dispenser; 7 crystallizer wheel; 8 - annular groove 


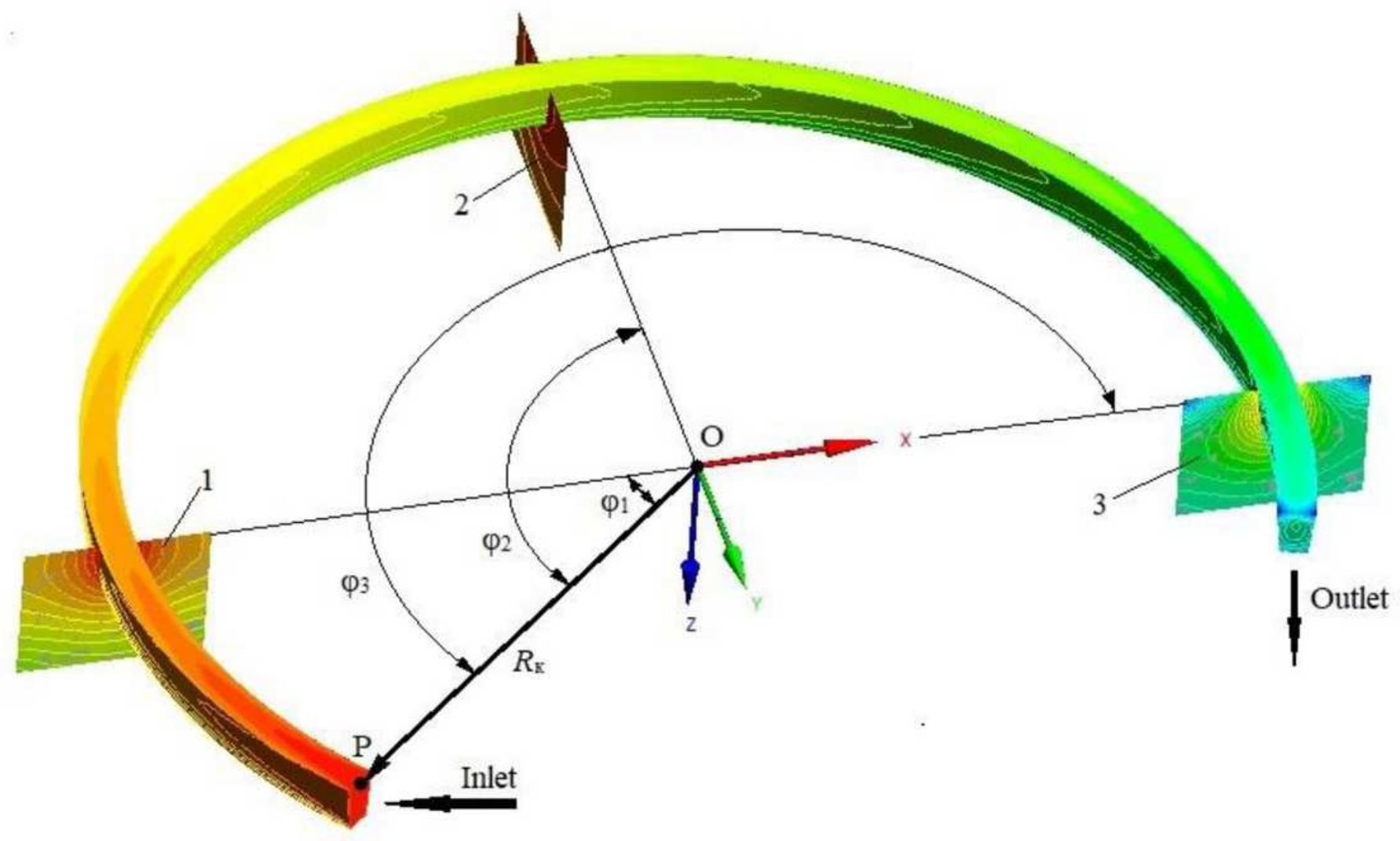

Figure 2

The layout of the design sections in the body of the horizontal mold from the place of pouring the melt $\mathrm{P}$ :

1,2 and $3-$ design sections, at central angles $\varphi 1=30^{\circ}, \varphi 2=120^{\circ}$ and $\varphi 3=210^{\circ}$ 


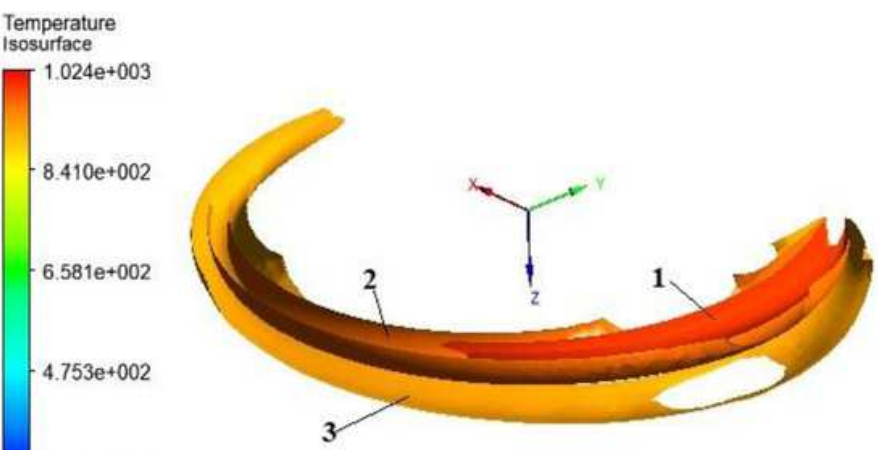

$2.924 \mathrm{e}+002$

[K]

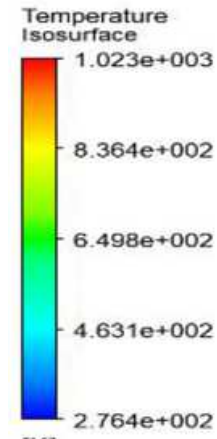

[K]

$\sim$

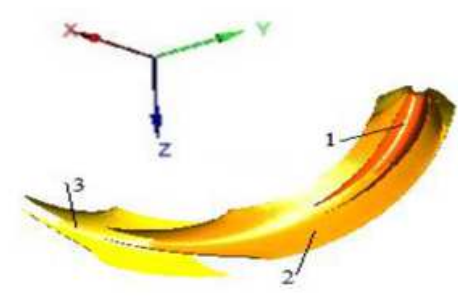

$c$

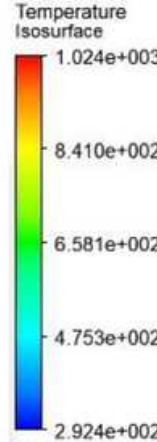

[K]

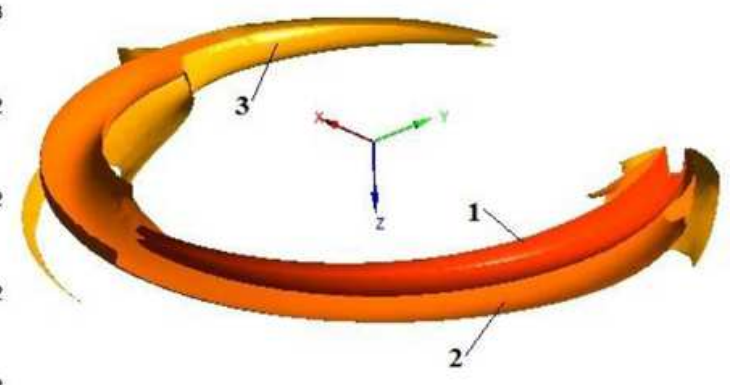

$h$

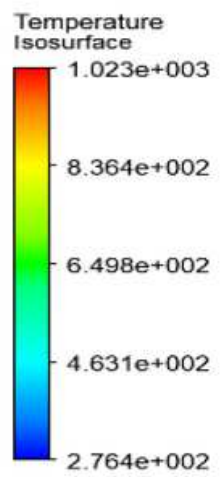

$[\mathrm{K}]$

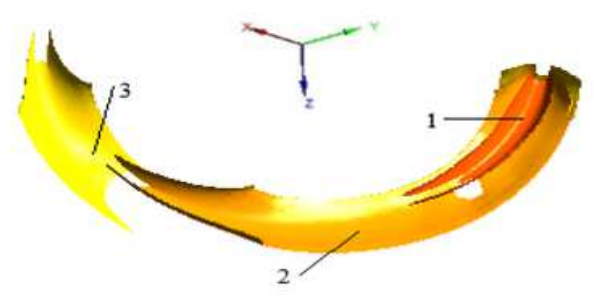

$d$

\section{Figure 3}

The values of the isotherms ti in the body of the mold in the transient thermal process at tp $=750{ }^{\circ} \mathrm{C}: 1-$ $\mathrm{t} 1=700^{\circ} \mathrm{C} ; 2-\mathrm{t} 2=650^{\circ} \mathrm{C} ; 3-\mathrm{t} 3=600^{\circ} \mathrm{C} ; \mathrm{a}-$ tex $=320 \mathrm{~s}, \mathrm{wk}=3 \mathrm{rpm} ; \mathrm{b}-\mathrm{tex}=840 \mathrm{~s}, \mathrm{wk}=3 \mathrm{rpm} ; \mathrm{c}-$ $\tau e x=320 \mathrm{~s}, w k=1 \mathrm{rpm} ; \mathrm{d}-\tau e x=840 \mathrm{~s}, w \mathrm{wk}=1 \mathrm{rpm}$ 


Temperature
Silumin
\begin{tabular}{|l}
\hline-965.6 \\
-916.8 \\
-868.0 \\
-819.2 \\
-770.4 \\
-721.6 \\
-672.8 \\
-624.0 \\
-575.2 \\
-526.4 \\
-477.7 \\
-428.9 \\
380.1 \\
331.3 \\
282.5
\end{tabular}

$[\mathrm{K}]$

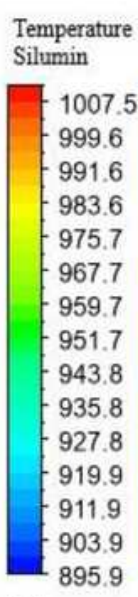

[K]

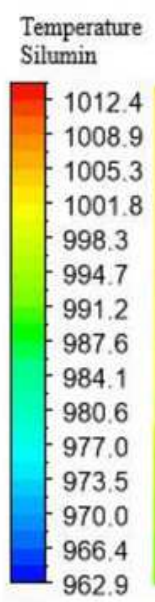

$[\mathrm{K}]$
Temperature Cristallyzer

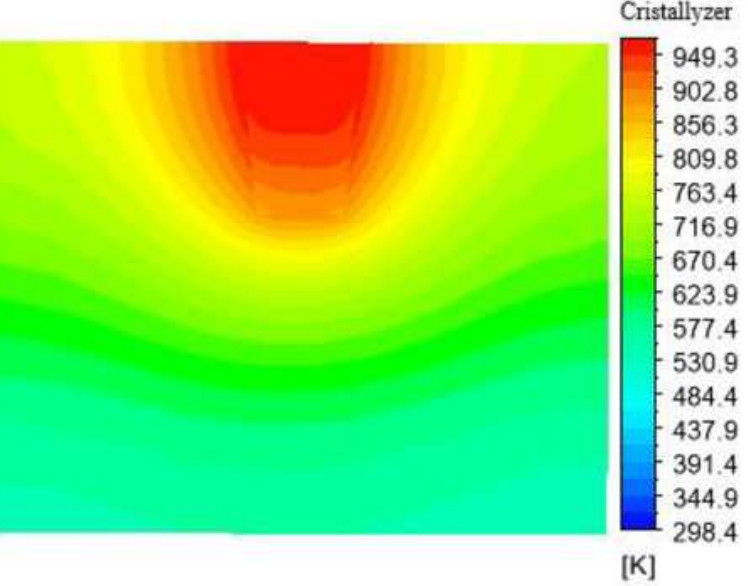

$a$

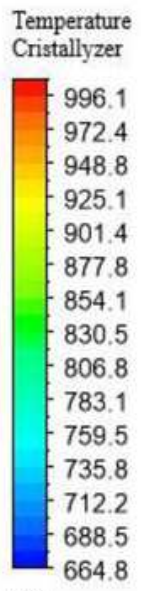

$[\mathrm{K}]$

$b$

Temperature Cristallyzer

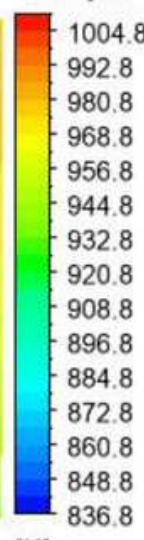

[K]

\section{Figure 4}

Temperature field $(\mathrm{K})$ in the design section of the metal and the mold $\varphi 1=30^{\circ}$ at $\mathrm{tp}=750^{\circ} \mathrm{C}$, wk $=3 \mathrm{rpm}$ : $a-\tau e x=60 \mathrm{~s} ; b-\tau e x=320 \mathrm{~s} ; c-$ stationary thermal regime 

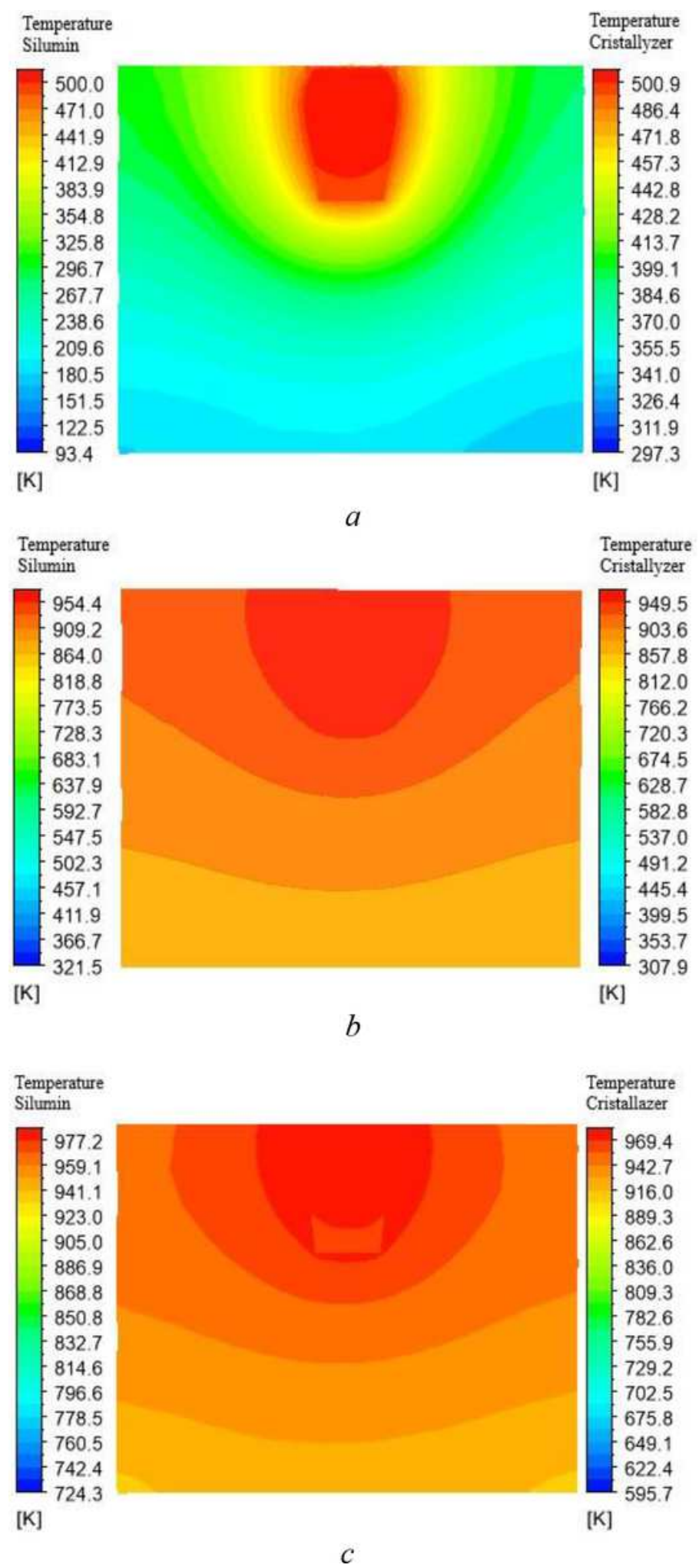

\section{Figure 5}

Temperature field $(K)$ in the design section of the metal and the mold $\varphi 1=30^{\circ}$ at tp $=750{ }^{\circ} \mathrm{C}$, wk $=1 \mathrm{rpm}$ : $a-\tau e x=60 \mathrm{~s} ; \mathrm{b}-\tau$ tex $=450 \mathrm{~s} ; \mathrm{c}-$ stationary thermal regime 


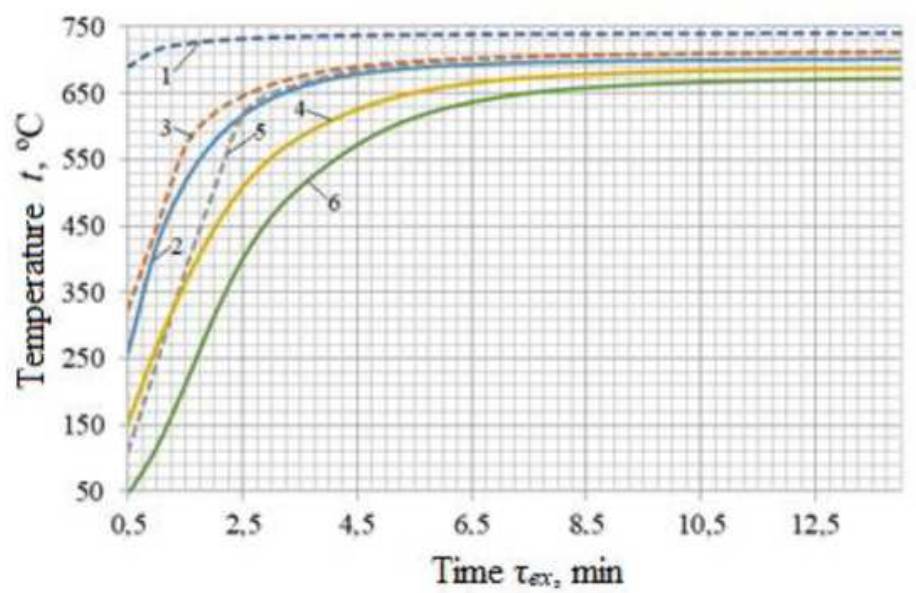

$a$
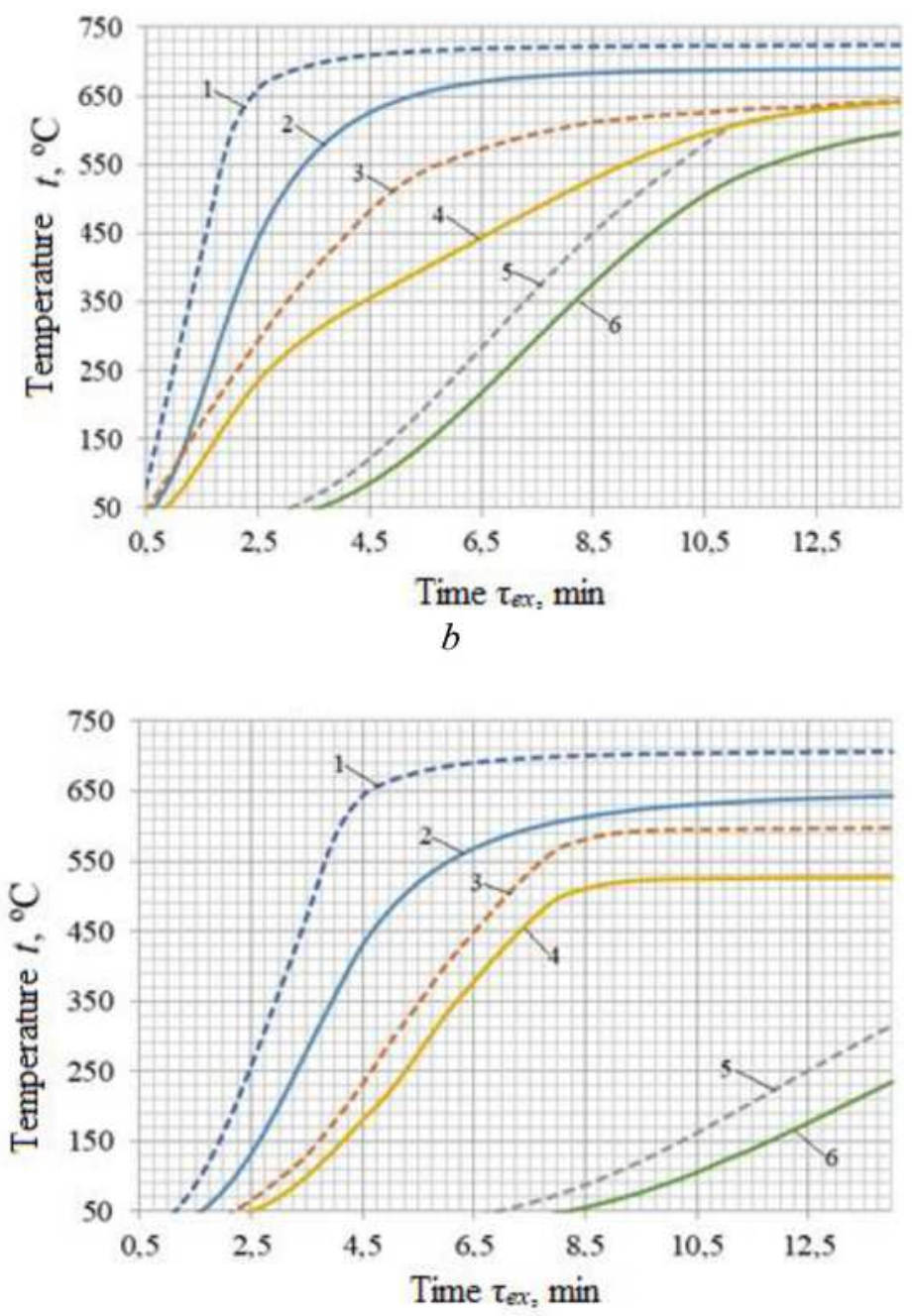

$c$

\section{Figure 6}

Temperature change in the body of the mold and metal in the design sections $\varphi \mathrm{i}$ in transient thermal mode: 1, 2 - temperature of metal and mold at $w \mathrm{k}=3 \mathrm{rpm} ; 3,4-$ temperature of metal and mold at wk = $2 \mathrm{rpm} ; 5,6$ - temperature of metal and mold at $w \mathrm{k}=1 \mathrm{rpm} ; \mathrm{a}-\varphi 1=30^{\circ} ; \mathrm{b}-\varphi 2=120^{\circ} ; \mathrm{c}-\varphi 3=210^{\circ}$ 